\title{
Percutaneous cryoablation for hepatocellular carcinoma
}

\author{
Kyoung Doo Song \\ Department of Radiology and Center for Imaging Science, Samsung Medical Center, Sungkyunkwan University School of Medicine, \\ Seoul, Korea
}

Local ablation therapy is considered as a conventional treatment option for patients with early stage hepatocellular carcinoma (HCC). Although radiofrequency (RF) ablation is widely used for HCC, the use of cryoablation has been increasing as newer and safer cryoablation systems have developed. The thermodynamic mechanism of freezing and thawing used in cryoablation is the Joule-Thomson effect. Cryoablation destroys tissue via direct tissue destruction and vascular-related injury. A few recent comparative studies have shown that percutaneous cryoablation for HCCs is comparable to percutaneous RF ablation in terms of long term therapeutic outcomes and complications. Cryoablation has several advantages over RF ablation such as well visualization of iceball, no causation of severe pain, and lack of severe damage to great vessels and gallbladder. It is important to know the advantages and disadvantages of cryoablation compared with RF ablation for improvement of therapeutic efficacy and safety. (Clin Mol Hepatol 2016;22:509-515)

Keywords: Cryoablation; Hepatocellular carcinoma; Radiofrequency ablation

\section{INTRODUCTION}

Local ablation therapy is considered as a conventional treatment option for patients with early stage hepatocellular carcinoma (HCC) according to the latest Barcelona Clinic Liver Cancer (BCLC) classification system. 'Local ablation modalities can be divided into chemical ablation and energy-based ablation. ${ }^{2}$ Ethanol ablation is a representative therapy of chemical ablation for HCC. Energy-based ablation includes radiofrequency (RF) ablation, microwave ablation, cryoablation, ultrasound ablation, laser ablation, and irreversible electroporation. Among these local ablation modalities, the first-line technique is now RF ablation. ${ }^{3}$ Although RF ablation is the most commonly used ablation modality, the use of other modalities such as cryoablation or microwave ablation has been increasing. Microwave ablation uses heat to destroy a tumor similar to RF ablation, but cryoablation uses cold. Because of its different mechanism of tumor ablation, cryoablation has several potential advantages over RF ablation. This article aims at reviewing the mechanisms, technique, treatment outcomes of cryoablation and suggesting potential indications of cryoablation for treatment of HCC.

\section{MECHANISMS}

\section{Mechanism of tissue freezing and thawing}

Cryoablation destroys tissue by the application of alternating freezing and thawing. The thermodynamic mechanism of freezing and thawing is based on the Joule-Thomson effect. The Joule-

\section{Abbreviations:}

ALT, alanine aminotransferase; AST, aspartate aminotransferase; BCLC, Barcelona Clinic Liver Cancer; CBC, complete blood count; CT, computed tomography; $M R I$, magnetic resonance imaging; PSI, pound-force per square inch; HCC, hepatocellular carcinoma; RF, radiofrequency; US, ultrasound

\section{Corresponding author : Kyoung Doo Song}

Department of Radiology and Center for Imaging Science, Samsung Medical Center, Sungkyunkwan University School of Medicine, 81 IrwonRo, Gangnam-Gu, Seoul 06351, Korea

Tel: +82.2-3410-2519, Fax: +82.2-3410-0049

E-mail:kd3893.song@samsung.com 


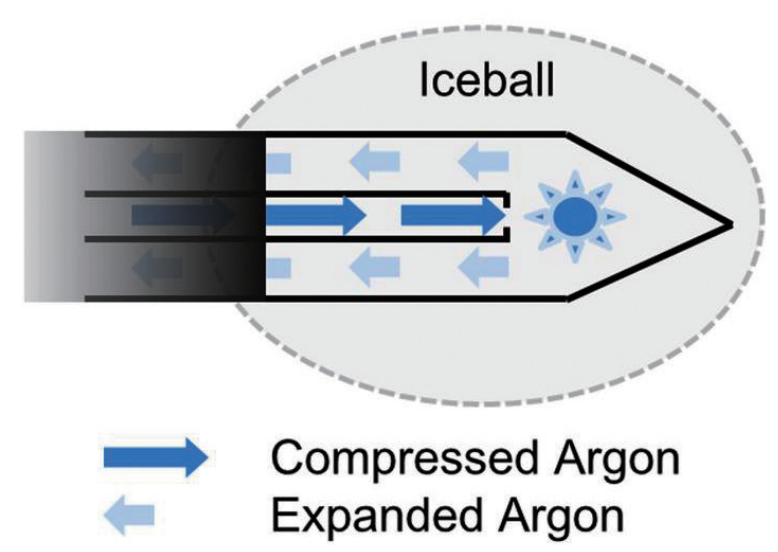

Figure 1. Joule-Thomson effect. As compressed argon gas is delivered to the tip of the cryoprobe in a closed circuit and expanded through a minute pore, gas pressure falls, and it decreases its temperature.

Thomson effect describes the temperature change of a gas when it is forced through a valve while kept insulated so that no heat is exchanged with the environment (Fig. 1). In cryoablation, as compressed gas is delivered to the tip of the cryoprobe in a closed circuit and expanded through a minute pore, gas pressure falls, and it changes its temperature. The currently available cryosystems use argon gas and helium gas. For argon gas, the expansion results in reduction of the temperature and freezing under higher pressures (3,500 pound-force per square inch [PSI]). On the other hand, helium gas releases energy to the environment, thereby generates heat when it expands. In the cryosystems using both argon gas and helium gas, argon gas is used for freezing and helium gas is used for thawing. On the other hand, cryotechnology that uses only argon gas for both freezing and thawing has been introduced. This system has an additional electrical heating source embedded in the cryoprobe. Joule-Thompson coefficients of gases vary with pressure and temperature. For argon gas, cooling effect becomes negligible when the gas expands under lower pressure (200-500 PSI). In this modified cryotechnology, argon gas is used for freezing and also used to heat the cryoprobe shaft by spreading the heat generated by an electrical heating source embedded in the cryoprobe for thawing.

\section{Mechanisms of tissue destruction}

There are two main mechanisms of tissue destruction in cryoablation: direct cellular injury and vascular-related injury. ${ }^{4,5}$ Direct cellular injury relies on ice crystal formation in extracellular and intracellular spaces. As the temperature falls into the freezing range, ice crystal formation first occurs in the extracellular spaces.
Extracellular ice formation withdraws water from the extracellular environment and induces hyperosmotic extracellular environment that in turn draws water from the cells. As this process continues, ice crystals grow, cells are dehydrated, and membranes and enzymes are damaged. With further cooling, intracellular ice crystal formation occurs. The cell membrane can be a barrier to ice crystal formation to temperatures of about -7 to $-10^{\circ} \mathrm{C}$. May cells contain ice crystals by $-15^{\circ} \mathrm{C}$ and all water in transformed to ice below $-40^{\circ} \mathrm{C}$. Intracellular ice crystals disrupt cell membrane and damage vital cell structures mechanically. This intracellular ice crystal formation occurs with rapid freezing rates. Direct cellular injury occurs in process of thawing as well as freezing. When the temperature of frozen tissue rises above $-40^{\circ} \mathrm{C}$ and especially -20 and $-25^{\circ} \mathrm{C}$, ice crystals fuse to from large crystals, and additional damage occurs in the cellular structures. In addition, as the ice crystals melts, the extracellular space become hypotonic state, and water move into the damaged cells, and cell membranes may rupture.

The second mechanism of tissue injury is vascular-related injury. As the temperature of tissue falls, vasoconstriction and a decrease in the flow of blood occur, and finally the circulation stops. As a result, inflammatory change and tissue ischemia or necrosis are induced. During the thawing phase, brief hyperemic change and increased vascular permeability occurs. These changes enhance endothelial damage, which results in increased permeability of the capillary, edema, platelet aggregation, and microthrombus formation. As a result, many small blood vessels are completely occluded, and tissue necrosis occurs.

\section{PROCESS OF PERCUTANEOUS CRYOABLATION}

\section{Patient selection}

Indication of percutaneous cryoablation for HCC is similar to that of other local ablation therapies, especially RF ablation: (1) patient with a single $\mathrm{HCC}$ less than $5 \mathrm{~cm}$ in diameter, or up to three HCCs less than $3 \mathrm{~cm}$ in diameter (ie, within the Milan criteria), (2) absence of portal venous thrombosis, (3) Child-Pugh class A or B, (4) no significant coagulopathy. ${ }^{6}$

\section{Technique}

Targeting of the tumor and monitoring of cryoablation can be performed under the guidance of ultrasound (US), computed tomography (CT), and magnetic resonance imaging (MRI). ${ }^{7-10}$ On US, 

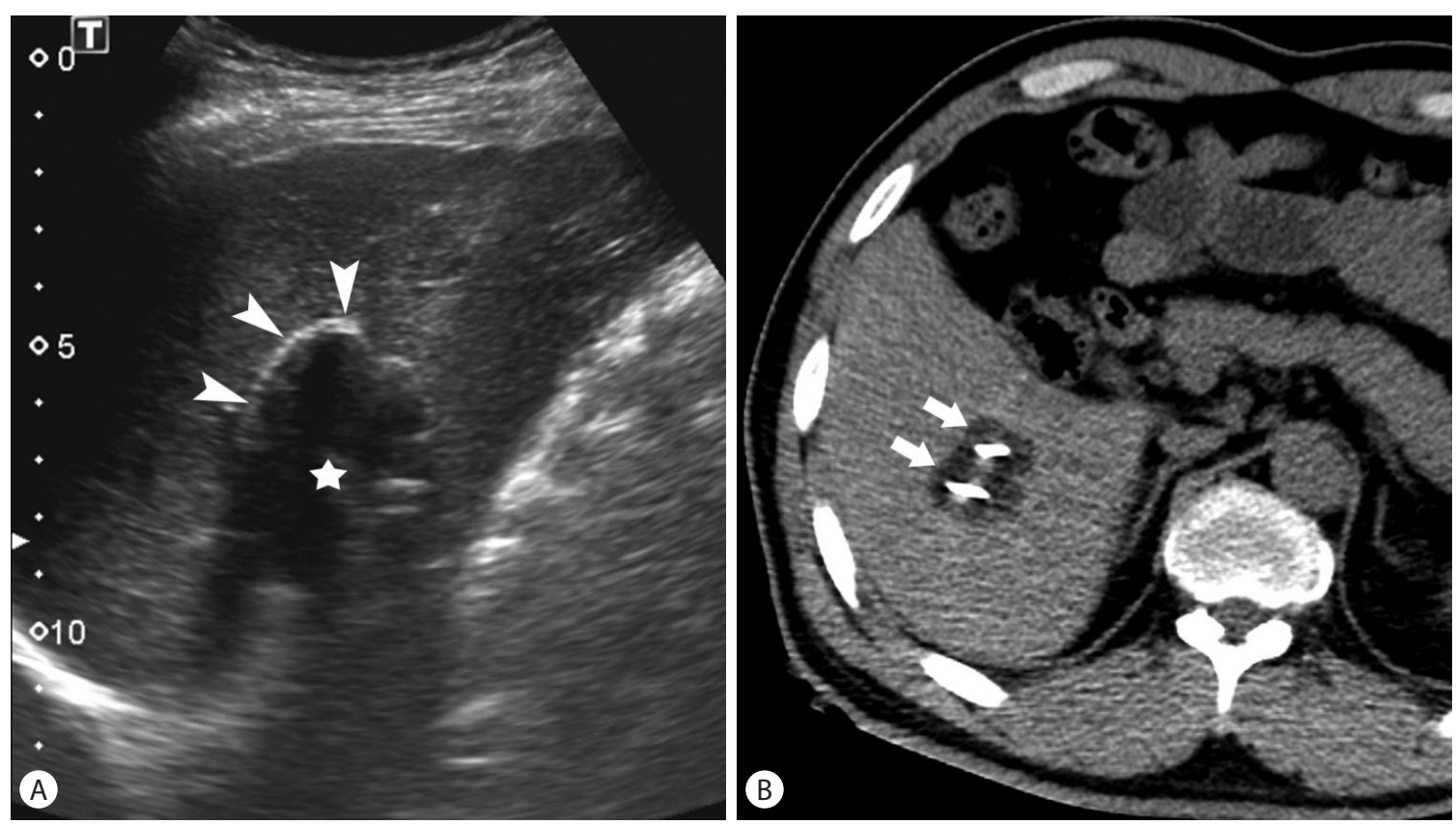

Figure 2. Iceball on ultrasound (A) and computed tomography (B). On US, the ice ball is seen as hyperechoic line (arrowheads) representing the proximal edge of the ice ball with posterior acoustic shadow (white star). On CT, the ice ball is identified as low attenuation ( O HU) region (arrows).

the ice ball is seen as hyperechoic line representing the proximal edge of the ice ball with posterior acoustic shadow (Fig. 2A). The ice ball is identified as low attenuation ( $0 \mathrm{HU})$ region on CT (Fig. 2B) and signal void region on MRI. Although MRI is a good imaging modality for monitoring cryoablation, US and $\mathrm{CT}$ are used in most practices because interventional MRI is only available in a limited number of center. Percutaneous cryoablation is usually performed under conscious sedation not general anesthesia. In contrast to other heat-based ablation modalities, cryoablation causes less pain. 11,12

To achieve complete tumor destruction, it is necessary to obtain appropriate ablative margin beyond the borders of the tumor. In general, 5-10 mm of ablative margin is acceptable for HCC. ${ }^{13}$ To obtain the ideal ablative margin, accurate placement of cryoprobes is essential. In general, the cryoprobes should be placed within $1 \mathrm{~cm}$ of the tumor border, with no more than $2 \mathrm{~cm}$ of separation between cryoprobes. ${ }^{14}$

During the cryoablation, ice ball formation can be visualized with US and CT. The temperature at the outer margin of ice ball is $0^{\circ} \mathrm{C}$. In one study, the relationship between the ice ball and the necrotic area after cryoablation was evaluated in the porcine liver, and the authors revealed that there was an approximately $1.1 \mathrm{~mm}$ gap between the margin of the visible ice ball and the zone of necrosis. ${ }^{15}$ It means that the size of ice ball on US or CT overestimates the size of true necrotic zone. This difference between the ice ball and the zone of necrosis is because of lethal temperature of cells. In experiments with the animal liver, the authors insisted that tissue temperatures in the range of -15 to $-20^{\circ} \mathrm{C}$ were adequate for destruction of normal liver tissue. ${ }^{16-19}$ However, cells have different susceptibility to freezing injury. Some malignant cells are resistant to injury at temperatures up to $-40^{\circ} \mathrm{C} \cdot{ }^{20-22} \mathrm{Al}-$ though there are a variety of opinions on the lethal temperature, the $-20^{\circ} \mathrm{C}$ is considered adequate to cause necrosis in watery tumors or tissues. ${ }^{14,23}$ Therefore, the margin of the iceball must exceed that of the tumor.

Cycle times of freezing and thawing influence the size of the iceball and the degree of necrosis. Repeated freezing and thawing cycles will increase the size of iceball $1^{24,25}$ and will induce more confluent and complete cellular death compared to a single cycle. ${ }^{26,27}$ Although an animal study revealed that a triple-freezing and thawing protocol produced a larger cryoablation zone of completer necrosis than a dual-freezing and thawing protocol ${ }_{1}^{28} \mathrm{a}$ dual-freezing and thawing protocol is widely accepted in clinical practice. The duration of freezing ranges from 10 to 20 minutes and the duration of thawing ranges from 5 to 10 minutes each cycle depending on reports. ${ }^{29-32}$

\section{Laboratory test after cryoablation}

Although cryoablation for hepatic tumors is relatively safe treat- 
ment modality, serious complications such as severe thrombocytopenia, liver failure, and cryoshock (multiorgan failure and disseminated intravascular coagulation) have been reported. ${ }^{33-36}$ According to one study, ${ }^{37}$ aspartate aminotransferase (AST) and alanine aminotransferase (ALT) values peaked at 6 hours after cryoablation. Although AST and ALT decreased at 1-2 weeks after procedure, the mean values at 1-2 weeks were slightly higher than those at baseline. The mean nadir in platelet count was seen at 12-24 hours after cryoablation and the value returned to baseline at 1 week. Myoglobin levels increased above normal in 44\% patients. The peak was seen at 6 hours and returned to baseline 1-2 weeks. Ablation volumes correlated with changes at 0-6 hours in AST, ALT and myoglobin values and percent maximal decrease in platelet count correlated with peak change in AST and ALT. Based on these results, recommendations for laboratory test after percutaneous cryoablation of liver tumors are as follows: complete blood count $(\mathrm{CBC})$, liver function tests, and myoglobin level at 6 hours; CBC at 12-24 hours; CBC and liver function tests at $1-2$ weeks.

\section{TREATMENT OUTCOMES: COMPARISION WITH RF ABLATION}

Although there are many studies that reported treatment outcomes of percutaneous cryoablation and RF ablation for hepatocellular carcinoma, comparative studies between two modalities are limited. There were four nonrandomized studies compared the outcomes of cryoablaton to RF ablation for hepatic malignancies in the late 1990s and the early 2000s..$^{38-41}$ According the metaanalysis based on these studies, RF ablation was significantly superior to cryoablation in terms of complications and local tumor progression. ${ }^{42}$ However, in these studies RF ablation and cryoablation were performed for various tumors including HCC and metastatic liver tumors and were performed under laparoscopic or intraoperative approaches as well as percutaneous approach. In addition, liquid nitrogen was used as a cryogen. However, recently percutaneous minimally invasive cryoablation with newer and safer cryoablation systems using thin cryoprobes and argon-helium as a cryogen have replaced. There are two recent studies that compared treatment outcomes between percutaneous cryoablation and RF ablation using these newer and safer cryoablation systems. ${ }^{31,43}$ Wang, et al. ${ }^{31}$ compared the percutaneous cryoablation and RF ablation in patients with one or two $\mathrm{HCCs} \leq 4 \mathrm{~cm}$. According to the study, local tumor progression rate was signifi- cantly lower in the cryoablation group than the RF ablation group $(5.6 \%$ versus $10 \%)$. For lesion $>3 \mathrm{~cm}$ in diameter, the difference of local tumor progression rate increased (7.7\% versus $18.2 \%)$. Lower local tumor progression rate for HCCs with relatively large size was reported in the study of Ei et al. although cryoablation and RF ablation were performed percutaneously or intraoperatively in the study. ${ }^{32}$ This may be attributable to the potential advantages of cryoablation over RF ablation in producing larger ablation zones with multiple probes. According to the study of Wang et $a^{1}{ }^{31}$, the recurrence free survival rate and overall survival rate were not significantly different between two group. In terms of complication, the major complication rate between percutaneous cryoablation and RF ablation was comparable. The major complication rate was 3.9\% following cryoablation and 3.3\% following RF ablation in the study of Wang et al. ${ }^{31}$ and $6.1 \%$ following cryoablation and 3.3\% following RF ablation in the study of Dunne et al. ${ }^{43}$ In both two studies, there was no treatment-related mortality, renal insufficiency, or coagulopathy in either group.

\section{ADVANTAGES OF CRYOABLATION}

\section{Well visualization of the iceball}

It is important to know the extent of tissue injury during local ablation therapy for achievement of technique success and avoidance of injury of critical organs. The edge of iceball during cryoablation is well visualized on CT and MRI. The anterior edge of iceball is also well visualized on US although it is difficult to evaluate the posterior edge of iceball because of posterior shadowing. In addition, the size of iceball correlates with the extent of tissue injury well although the size of iceball is slightly larger than that of tissue injury. Therefore, cryoablation has advantages in monitoring the extent of tissue injury during procedure.

\section{No causation of severe pain}

Percutaneous ablation therapy is usually performed under conscious sedation. Heat-based ablation modalities such as RF ablation and microwave ablation can cause severe pain. The severe pain sometimes interferes with appropriate completion of the planned ablation. In contrast to heat-based ablation modalities, cryoablation is a relatively painless procedure and thus patients are usually stable during procedure. 


\section{Lack of severe damage to large blood vessels}

RF ablation can cause thermal injury of portal and hepatic veins. Recently, a study reported that RF ablation induced hepatic parenchymal hypoperfusion caused by portal vein obstruction or congestion from hepatic vein damage is a significant predictor of recurrence after RF ablation of HCCs. ${ }^{44}$ In addition, there have been several experimental studies in which it was reported that ischemia-reperfusion injury of the liver can promote cancer cell growth. ${ }^{45,46}$ On the other hand, vascular patency was maintained and structural function was preserved after cryoablation because of maintained elastin fiber composition in an animal study which was performed on murine abdominal aorta although smooth muscle cells were vacuolated and eventually dead. ${ }^{47}$

\section{Lack of severe damage to gallbladder}

According to a study, no gallbladder-related complications occurred after cryoablation for hepatic tumors adjacent to the gallbladder although the iceballs extended into the gallbladder lumen. ${ }^{48}$ There was only mild, asymptomatic focal wall thickening on imaging studies, which resolved on follow-up.

\section{CONCLUSION}

Several clinical studies have shown that long term therapeutic outcomes of percutaneous cryoablation for HCCs are comparable to those of percutaneous RF ablation. Even percutaneous cryoablation have shown superior local tumor control for relatively large HCCs. In the initial period of hepatic cryoablation, the rate of severe complications was high. However, newer and safer cryoablation system has been developed and recently the complication rate after hepatic cryoablation became similar to that of percutaneous RF ablation. In addition, cryoablation has several advantages over RF ablation such as well visualization of iceball, no causation of severe pain, and lack of severe damage to great vessels and gallbladder. It is important to know the advantages and disadvantages of each ablation modalities for improvement of therapeutic efficacy and safety.

\section{Conflicts of Interest}

The author has no conflicts to disclose.

\section{REFERENCES}

1. Forner A, Llovet JM, Bruix J. Hepatocellular carcinoma. Lancet 2012;379:1245-1255.

2. Ahmed M, Solbiati L, Brace CL, Breen DJ, Callstrom MR, Charboneau JW, et al. Image-guided tumor ablation: standardization of terminology and reporting criteria--a 10-year update. Radiology 2014;273:241-260.

3. Lencioni R. Loco-regional treatment of hepatocellular carcinoma. Hepatology 2010;52:762-773.

4. Hoffmann NE, Bischof JC. The cryobiology of cryosurgical injury. Urology 2002;60:40-49.

5. Gage AA, Baust J. Mechanisms of tissue injury in cryosurgery. Cryobiology 1998;37:171-186.

6. Kim YS, Lim HK, Rhim H, Lee MW, Choi D, Lee WJ, et al. Ten-year outcomes of percutaneous radiofrequency ablation as first-line therapy of early hepatocellular carcinoma: analysis of prognostic factors. J Hepatol 2013;58:89-97.

7. Lee FT Jr, Chosy SG, Littrup PJ, Warner TF, Kuhlman JE, Mahvi DM. CT-monitored percutaneous cryoablation in a pig liver model: pilot study. Radiology 1999;211:687-692.

8. Silverman SG, Sun MR, Tuncali K, Morrison PR, vanSonnenberg E, Shankar $S$, et al. Three-dimensional assessment of MRI-guided percutaneous cryotherapy of liver metastases. AJR Am J Roentgenol 2004;183:707-712.

9. Gilbert JC, Onik GM, Hoddick WK, Rubinsky B. Real time ultrasonic monitoring of hepatic cryosurgery. Cryobiology 1985;22:319-330.

10. Tacke J, Adam G, Haage P, Sellhaus B, Grosskortenhaus S, Günther RW. MR-guided percutaneous cryotherapy of the liver: in vivo evaluation with histologic correlation in an animal model. J Magn Reson Imaging 2001;13:50-56.

11. Permpongkosol S, Sulman A, Solomon SB, Gong GX, Kavoussi LR. Percutaneous computerized tomography guided renal cryoablation using local anesthesia: pain assessment. J Urol 2006;176:915-918.

12. Allaf ME, Varkarakis IM, Bhayani SB, Inagaki T, Kavoussi LR, Solomon SB. Pain control requirements for percutaneous ablation of renal tumors: cryoablation versus radiofrequency ablation--initial observations. Radiology 2005;237:366-370.

13. Ahmed M, Brace CL, Lee FT Jr, Goldberg SN. Principles of and advances in percutaneous ablation. Radiology 2011;258:351-369.

14. Hinshaw JL, Lee FT, Jr. Cryoablation for liver cancer. Tech Vasc Interv Radiol 2007;10:47-57.

15. Weber SM, Lee FT Jr, Warner TF, Chosy SG, Mahvi DM. Hepatic cryoablation: US monitoring of extent of necrosis in normal pig liver. Radiology 1998;207:73-77.

16. Rivoire ML, Voiglio EJ, Kaemmerlen P, Molina G, Treilleux I, Finzy J, et al. Hepatic cryosurgery precision: evaluation of ultrasonography, thermometry, and impedancemetry in a pig model. J Surg Oncol 
$1996 ; 61: 242-248$

17. Smith JJ, Fraser J. An estimation of tissue damage and thermal history in the cryolesion. Cryobiology 1974;11:139-147.

18. Smith JJ, Fraser J, Maclver AG. Ultrastructure after cryosurgery of rat liver. Cryobiology 1978;15:426-432.

19. Permpongkosol S, Nicol TL, Link RE, Varkarakis I, Khurana H, Zhai QJ, et al. Differences in ablation size in porcine kidney, liver, and lung after cryoablation using the same ablation protocol. AJR Am J Roentgenol 2007;188:1028-1032.

20. Ikekawa S, Ishihara K, Tanaka S, Ikeda S. Basic studies of cryochemotherapy in a murine tumor system. Cryobiology 1985;22:477-483.

21. Zacarian SA. The observation of freeze-thaw cycles upon cancer-cell suspensions. J Dermatol Surg Oncol 1977;3:173-174.

22. Seifert JK, Gerharz CD, Mattes F, Nassir F, Fachinger K, Beil C, et al. A pig model of hepatic cryotherapy. In vivo temperature distribution during freezing and histopathological changes. Cryobiology 2003:47:214-226.

23. Niu LZ, Li JL, Xu KC. Percutaneous Cryoablation for Liver Cancer. J Clin Transl Hepatol 2014;2:182-188.

24. Whittaker DK. Repeat freeze cycles in cryosurgery of oral tissues. $\mathrm{Br}$ Dent J 1975;139:459-465.

25. Mala T, Edwin B, Tillung T, Kristian Hol P, Søreide O, Gladhaug I. Percutaneous cryoablation of colorectal liver metastases: potentiated by two consecutive freeze-thaw cycles. Cryobiology 2003;46:99-102.

26. Muller-Schweinitzer E. Arterial smooth muscle function after prolonged exposure to a medium containing dimethyl sulfoxide (Me2SO) and storage at -196 degrees C. Cryobiology 1994;31:330-335.

27. Clarke DM, Robilotto AT, Rhee E, VanBuskirk RG, Baust JG, Gage $A A$, et al. Cryoablation of renal cancer: variables involved in freezing-induced cell death. Technol Cancer Res Treat 2007;6:69-79.

28. Li J, Chen J, Zhou L, Zeng J, Yao F, Wu B, et al. Comparison of dualand triple-freeze protocols for hepatic cryoablation in a Tibet pig model. Cryobiology 2012;65:68-71.

29. Lee SM, Won JY, Lee DY, Lee KH, Lee KS, Paik YH, et al. Percutaneous cryoablation of small hepatocellular carcinomas using a 17-gauge ultrathin probe. Clin Radiol 2011;66:752-759.

30. Kim GM, Won JY, Kim MD, Park SI, Lee do Y, Shin W, et al. Cryoablation of Hepatocellular Carcinoma with High-Risk for Percutaneous Ablation: Safety and Efficacy. Cardiovasc Intervent Radiol 2016:39:1447-1454.

31. Wang C, Wang H, Yang W, Hu K, Xie H, Hu KQ, et al. Multicenter randomized controlled trial of percutaneous cryoablation versus radiofrequency ablation in hepatocellular carcinoma. Hepatology 2015;61:1579-1590.

32. Ei S, Hibi T, Tanabe M, Itano O, Shinoda M, Kitago M, et al. Cryoablation provides superior local control of primary hepatocellular carcinomas of $>2 \mathrm{~cm}$ compared with radiofrequency ablation and microwave coagulation therapy: an underestimated tool in the tool- box. Ann Surg Oncol 2015;22:1294-1300.

33. Cozzi PJ, Stewart GJ, Morris DL. Thrombocytopenia after hepatic cryotherapy for colorectal metastases: correlates with hepatocellular injury. World J Surg 1994;18:774-776.

34. Hamad GG, Neifeld JP. Biochemical, hematologic, and immunologic alterations following hepatic cryotherapy. Semin Surg Oncol 1998;14:122-128.

35. Onik G, Rubinsky B, Zemel R, Weaver L, Diamond D, Cobb C, et al. Ultrasound-guided hepatic cryosurgery in the treatment of metastatic colon carcinoma. Preliminary results. Cancer 1991;67:901907.

36. Shafir M, Shapiro R, Sung M, Warner R, Sicular A, Klipfel A. Cryoablation of unresectable malignant liver tumors. Am J Surg 1996:171:27-31.

37. Nair RT, Silverman SG, Tuncali K, Obuchowski NA, vanSonnenberg E, Shankar S. Biochemical and hematologic alterations following percutaneous cryoablation of liver tumors: experience in 48 procedures. Radiology 2008;248:303-311.

38. Pearson AS, Izzo F, Fleming RY, Ellis LM, Delrio P, Roh MS, et al. Intraoperative radiofrequency ablation or cryoablation for hepatic malignancies. Am J Surg 1999;178:592-599.

39. Tait IS, Yong SM, Cuschieri SA. Laparoscopic in situ ablation of liver cancer with cryotherapy and radiofrequency ablation. Br J Surg 2002:89:1613-1619.

40. Bilchik AJ, Wood TF, Allegra D, Tsioulias GJ, Chung M, Rose DM, et al. Cryosurgical ablation and radiofrequency ablation for unresectable hepatic malignant neoplasms: a proposed algorithm. Arch Surg 2000;135:657-662; discussion 662-654.

41. Adam R, Hagopian EJ, Linhares M, Krissat J, Savier E, Azoulay D, et al. A comparison of percutaneous cryosurgery and percutaneous radiofrequency for unresectable hepatic malignancies. Arch Surg 2002;137:1332-1339; discussion 1340.

42. Huang $Y Z$, Zhou SC, Zhou H, Tong M. Radiofrequency ablation versus cryosurgery ablation for hepatocellular carcinoma: a metaanalysis. Hepatogastroenterology 2013;60:1131-1135.

43. Dunne RM, Shyn PB, Sung JC, Tatli S, Morrison PR, Catalano PJ, et al. Percutaneous treatment of hepatocellular carcinoma in patients with cirrhosis: a comparison of the safety of cryoablation and radiofrequency ablation. Eur J Radiol 2014;83:632-638.

44. Lee DH, Lee JM, Yoon JH, Kim YJ, Han JK. Thermal Injury-induced Hepatic Parenchymal Hypoperfusion: Risk of Hepatocellular Carcinoma Recurrence after Radiofrequency Ablation. Radiology 2016 Sep 19:152322. [Epub ahead of print]

45. Ku Y, Kusunoki N, Shiotani M, Maeda I, Iwasaki T, Tominaga M, et al. Stimulation of haematogenous liver metastases by ischaemiareperfusion in rats. Eur J Surg 1999;165:801-807.

46. van der Bilt JD, Kranenburg O, Nijkamp MW, Smakman N, Veenendaal LM, Te Velde EA, et al. Ischemia/reperfusion accelerates 
Kyoung Doo Song.

Cryoablation for HCC

the outgrowth of hepatic micrometastases in a highly standardized murine model. Hepatology 2005;42:165-175.

47. Ladd AP, Rescorla FJ, Baust JG, Callahan M, Davis M, Grosfeld JL. Cryosurgical effects on growing vessels. Am Surg 1999;65:677-682.
48. Fairchild AH, Tatli S, Dunne RM, Shyn PB, Tuncali K, Silverman SG. Percutaneous cryoablation of hepatic tumors adjacent to the gallbladder: assessment of safety and effectiveness. J Vasc Interv Radiol 2014;25:1449-1455. 